\title{
DO CORPO QUE DISTINGUE MENINOS E MENINAS NA EDUCAÇÃO FÍSICA ESCOLAR
}

\author{
Priscila Gomes Dornelles*
}

\begin{abstract}
RESUMO: Decorrente de uma pesquisa de mestrado e inscrito na intersecção entre os estudos culturais, feministas e de gênero, particularmente na vertente pós-estruturalista, este artigo problematiza que o discurso biológico atravessa e constitui as justificativas enunciadas por professores/as para separar meninos e meninas na educação física escolar. Como estratégias metodológicas, utilizei questionários para identificar e, posteriormente, entrevistar dez professores/as da rede municipal de ensino de Porto Alegre que separassem os/as estudantes nas suas aulas. Utilizando-me da análise de discurso, suspeito dos essencialismos e das naturalizaçóes como mecanismos estabelecidos por este discurso, numa tentativa de fixar o corpo como construto biológico - origem e explicação da divisão nesta disciplina escolar -, para marcá-lo como construção cultural.
\end{abstract}

Palavras-chave: Corpo. Gênero. Idade. Educação física escolar. Separação de meninos e meninas.

THE BODY THAT DISTINGUISHES BOYS AND GIRLS IN SCHOOL PHYSICAL EDUCATION

ABSTRACT: Resulting from a master's degree research and enrolled at the intersection of cultural, feminist and gender studies, particularly in the poststructuralist strand, this article brings the problematic of a biological discourse that goes through and constitutes the justifications given by teachers to separate boys and girls

Doutoranda no Programa de Pós-Graduação em Educação da Universidade Federal do Rio Grande do Sul (UFRGS) e professora do Centro de Formação de Professores da Universidade Federal do Recôncavo da Bahia (UFRB). E-mail: prisciladornelles@gmail.com. 
Do corpo que distingue meninos e meninas na educação física escolar

in school physical education. As methodological strategy, questionnaires were used to identify and subsequently interview ten teachers from Porto Alegre's municipal schools that would separate boys and girls in their classes. Using the discourse analysis, I suspect of essentialisms and naturalizations as mechanisms established by this speeches, attempting to set the body as a biological construct - the origin and explanation of the separation in such school discipline - in order to mark it as a cultural construct.

Key words: Body. Gender. Age. Physical education. Separation of boys and girls.

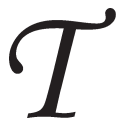

omo como mola propulsora a argumentação construída por Gallo (2006, p. 254) acerca das aproximaçóes e potencialidades da produção filosófica foucaultiana como exercício para pensarmos o campo da educação:

Se a Filosofia, como afirma Foucault, é este exercício e suspeita, esta busca inquietante por aquilo que ainda não pensamos, esta interrogação sobre a própria maneira de nos conduzirmos, então a Filosofia da Educação precisa ser um questionar-se sobre as certezas prontas do universo educacional.

É um movimento próximo do que propõe Corazza (2002) em seu texto, ao criar e utilizar a expressão "pesquisa-que-procura" para inserir uma ligação entre a ação de pesquisar e de ensinar que tensione outras possibilidades de deslocamento e de exercício do pensamento na educação, e aqui incluo a educação física. De forma importante, a autora aponta que, para atrever-se na "pesquisa-que-procura”, é necessário um movimento de insatisfação com as certezas absolutas, um descontentamento "(...) que nos faz passar tanto tempo e tanto trabalho, dedicando-nos a ressignificar o que já estava significado” (p. 59).

Nesse sentido, provoco a insatisfação em sua positividade - uma positividade que atravessa a dimensão política das discussões que empreendo sobre corpo no decorrer deste texto e que serão talhadas, tendo como contexto as justificativas de docentes para separação de meninos e meninas na educação física escolar. Para lidar com esse movimento de questionamento, tensionamento e insatisfação, escrevo priorizando marcar o entendimento e a conceituação de corpo com os quais opero, ao 
mesmo tempo em que suspeito das certezas e das explicações simplificadas e naturalizadas que atribuem a uma marca biológica a possibilidade de dizer e classificar o que é um corpo.

De que corpo se fala...

A partir da perspectiva pós-estruturalista, privilegiando as contribuições de Michel Foucault, e movimentando-me pelos estudos feministas, culturais e de gênero, retomo o argumento de que a cultura é compreendida como "campo de luta entre os diferentes grupos sociais em torno da significação" (Silva, 2000, p. 32) para tensionar a posição que o corpo ocupa como apresentação inequívoca da identidade na contemporaneidade. Esse exercício de significação, no caso dos corpos, em geral, atribui às marcas biológicas o status de verdadeiras evidências dos sujeitos (de quem são os sujeitos). Entretanto, ao entender-se que as identidades (e as diferenças) se constituem através da relação identidade-diferença, é possível complexificar o processo, no sentido de entendêlo como instável, indefinido e estabelecido nas redes de poder-saber da cultura.

Desse modo, é importante marcar que o corpo é, sempre, resultado provisório e inacabado. Atravessado e constituído por categorias sociais como classe, geração, raça/etnia, gênero e sexualidade, pode ser compreendido de diversas formas. Conferir importância à cultura na fabricação dos corpos e dos sujeitos é entendê-los como produtos dos regimes discursivos contemporâneos que neles se inscrevem, marcando-os como corpos dotados de determinados significados (e não de outros) dentro do espaço escolar ou fora dele. Hall (1997) contribui na argumentação que ora desenvolvo ${ }^{1}$ ao desdobrar, em seu texto, como alguns conceitos são compreendidos após a virada cultural. Ele explica: "Dizer, portanto, que uma pedra é apenas uma pedra num determinado esquema discursivo ou classificatório não é negar que a mesma tenha existência material, mas é dizer que seu significado é resultante não de sua essência natural, mas de seu caráter discursivo" (p. 29).

Sant'Anna (2006), no princípio de um dos seus textos, pergunta e, ao mesmo tempo, dá pistas para pensarmos sobre a produtividade de trabalhar e pesquisar corpo e história. Para exemplificar como essa ligação é frutifera, a autora lança uma questão com relação ao tema 
Do corpo que distingue meninos e meninas na educação física escolar

do corpo: "como uma dada cultura ou um determinado grupo social criou maneiras de conhecê-lo e controlá-lo?” (p. 4). Na tentativa de compreender (e de responder) esse questionamento, a pesquisadora sinaliza a possibilidade de caracterizarmos uma dada cultura e um determinado período histórico através dos corpos, pois eles falam, exprimem, estampam as regras sociais e as (im)possibilidades de uma determinada época e/ou lugar. São "o mais belo traço da memória da vida" (Sant'Anna, op. cit., p. 57).

Ao voltar-me para a educação física escolar, especificamente para a separação de meninos e meninas, com o objetivo de oferecer elementos para compreensão (e suspeição) dos corpos nesse espaço institucional e pedagógico, é possível (e provável) que aí se atravessem características da contemporaneidade, regras sociais e marcas culturais de uma sociedade e significados compartilhados culturalmente. Desse modo, tratando-se do tema da separação, podem-se problematizar compreensóes de corpo produzidas nesse espaço pedagógico-institucional, mas, ao mesmo tempo, situar que ali se atravessam entendimentos compartilhados num espaço cultural mais amplo.

\section{Há uma idade para separar?}

Talvez a Educação Física, sobretudo a escolar, necessite refletir sobre sua adesão cega a modismos do deus mercado. Sobre sua ingenuidade e omissão frente à indústria do corpo. Sobre os fatalismos biológicos de fases de desenvolvimento e de faixas etárias, determinando o que se ensina em uma aula de Educação Física. (Soares, 2006b, p. 121)

Ao assumir que as identidades são produções linguísticas, o que proponho aqui é suspeitar da idade e da sua delimitação apenas no "tempo vivido pelo corpo" (Veiga-Neto, 2000, p. 217), para pensá-la como uma das categorias sociais, juntamente com tantas outras, como raça/ etnia, gênero e sexualidade, por exemplo, que se atravessam na constituição dos sujeitos. As articulações entre essas categorias produzem diferentes formas de identificar e de ser representado dentro da cultura e, ao mesmo tempo, produzem efeitos concretos. Como exemplo dessa afirmação, é possível discutir que, no caso da identidade geracional articulada com sexualidade, há diferenças entre ser homem, idoso e heterossexual e ser homem, idoso e homossexual. ${ }^{2}$ 
Veiga-Neto (op. cit., p. 217) contribui na discussão e sua preocupação com a articulação entre idade e educação relaciona-se com

(...) os processos pedagógicos das identidades etárias; com isso, refiro-me não apenas às "influências" que o pertencimento a esse ou àquele grupo etário pode trazer para a educação - escolarizada ou não -, como, também, aos processos pelos quais aprendemos (e ensinamos) a ter essa ou aquela idade.

Com isso, é possível suspeitar da idade apenas como produto biológico e demarcar que as identidades etárias, assim como as de gênero ou as sexuais, são móveis, visto que, de acordo com o trecho apresentado, os sentidos de ter essa ou aquela idade são construções possíveis na cultura.

E o que a educação física tem a ver com isso? A escola e a educação física escolar são tomadas como pedagogias que constituem significados sobre a idade, os quais são situados no contexto educacional escolar, especificamente, ou compartilhados de forma mais ampla, socialmente. No caso do tema da separação, a idade é enunciada pelos/as entrevistados/as como uma importante justificativa para dividir os/as estudantes nas aulas. De acordo com a análise das entrevistas, é como se, num determinado momento da vida escolar dos/as estudantes, houvesse impossibilidades para o trabalho misto, determinando a separação.

De acordo com o entrevistado Bernardo, ${ }^{3}$ por questôes culturais que são ensinadas fora da escola, há participação e atuação diferenciadas na escola entre meninos e meninas, o que gera a separação em alguns momentos. Mas ele acrescenta:

Que assim, até uma certa idade, meninos e meninas fazem parelho. Mas parelho mesmo. Até $\mathrm{A} 30^{4}$ é tranquilo. Na B10, começa um processo de diferenciação muito interessante, aonde, se a gente não convidar, não criar, não diversificar, elas acabam indo para esse lado onde culturalmente elas são colocadas, eu diria até, engavetadas. (Bernardo, 25/10/2006, p. 8)

No contexto dessa fala, é possível perceber uma noção que localiza os/as estudantes em duas grandes classificaçōes na educação física escolar, produzidas em relação ao tempo escolar e ao tempo vivido pelos corpos. Tomando como base a análise das entrevistas, posso afirmar que a classificação temporal escolar - que se associa às idades normais 
Do corpo que distingue meninos e meninas na educação física escolar

de trajetória educacional dos/as estudantes - é posicionada como referência para a utilização do trabalho misto ou separado com os/as alunos/as nas aulas da disciplina.

No caso desta rede de ensino, que se estrutura através dos ciclos de formação, há uma localização da idade como fator importante no regime de ensino. Cada ciclo é organizado de forma a acompanhar as características dos/as estudantes em suas diferentes idades. A escola opera com a idade não só no caso dos ciclos, mas também nas classificações dos seus níveis de ensino, seja no ensino seriado, seja nos ciclos de formação. Sua estrutura é idealizada para que haja uma correspondência gradativa e sequencial entre a idade dos/as estudantes e séries/anos-ciclos.

Com relação à separação, é possível afirmar que há a constituição discursiva de um marco divisor das trajetórias discentes, uma referência para separar. Os/as entrevistados/as referem-se aos ciclos B (entre 9 e 11 anos) e C (entre 12 e 14 anos), o que corresponde à pré-adolescência e à adolescência, respectivamente, segundo as orientaçôes legais dessa rede de ensino, como momento em que há necessidade de separação de meninos e meninas.

Há uma construção discursiva que significa de forma diferenciada meninos e meninas antes da adolescência e após essa fase, como se nesse período outros atributos constituíssem de forma decisiva os/as estudantes, o que, no caso da educação física escolar, impossibilitaria um trabalho misto. Esses atributos estão associados à construção corporal dos/as alunos/as e às suas formas de viver suas feminilidades e suas masculinidades. Dessa maneira, corpo, gênero e idade atravessam e constituem os diferentes discursos que justificam a necessidade de separação de meninos e meninas na educação física escolar, a partir de um determinado ano-ciclo/ciclo.

A professora Kássia, ao analisar se, no seu trabalho cotidiano, precisava ter uma ação pedagógica diferenciada com meninos e com meninas, afirma:

Tem! Eu acho que, em termos, assim, a guria é mais difícil de motivar e de exigir do que o guri na faixa etária em que eu trabalho, no C, com os maiores. Porque, se tu pegas os pequenos, para eles, está sempre tudo bom. E eles estão sempre a fim de tudo. E pra eles não existe "é menino ou é menina", tu consegues trabalhar junto e bem trabalhado. Agora, a partir ali do C, de C10, aí já tem as diferenças. A menina: "Ah! Porque tem seio, 
machuca! Eles chutam muito forte". A outra: "Eu vim de saia hoje"; "Estou de tamanco". Têm todas essas diferenças que os pequenos não têm, né. $\mathrm{E}$, para os pequenos, pra eles, é tudo igual, como se menino e menina fosse tudo igual. É mais fácil de trabalhar junto. (Kássia, 7/11/06, p. 2)

Outro entrevistado, ao comentar que a idade é um fator importante para a necessidade da separação, explica:

Eu acho que, a partir da quarta, quinta série, já poderia se fazer um trabalho separado. Quinta série, com certeza! Quarta, eu estou pensando, até porque é o momento em que eles começam a adquirir habilidades maiores e onde tu podes começar o trabalho do desporto com eles (...). Aí, sim, eu começo a perceber a questão da diferença, onde já poderiam se separar os dois sexos, os dois naipes pra conseguir um melhor resultado, um rendimento melhor na questão do saber aproveitar bem cada um deles. $\mathrm{O}$ menino, tu largas coisa pesada pra cima deles, em termos de treinamento, porque eles são, além de tudo, muito corajosos. É uma idade boa porque eles se arriscam, e a menina já tem muitos medos, já fica, muitas vezes, na questão do "nhénhénhé", na delicadeza, porque ela é mais sensível. Então, a gente tem que exatamente fazer um trabalho diferente com as meninas (...). Então, é isso que eu estou dizendo, é uma questão de rendimento mesmo, de um melhor aproveitamento e de conseguir mais rápido um resultado com cada um deles. E, se eu tiver eles juntos, um atrasa o outro. (Sérgio, 9/11/06, p. 8)

Walderdine (1999), referindo-se aos estudos sobre cultura popular e erotização de meninas, problematiza a concepção de criança como ser neutro socialmente. De acordo com a autora (p. 77), “(...) a natureza da criança não é descoberta, mas produzida em regimes de verdade criados naquelas mesmas práticas que proclamam o infante em todo o seu aspecto natural", configurando a infância como um estado de inocência e imaculação que deve ser cuidado para não desabrochar antes do tempo. Nesse sentido, pode-se tencionar uma representação de criança constituinte dos e constituída pelos excertos das entrevistas, nos quais me parece que as crianças são representadas como seres descorporificados, desgenerificados e assexualizados - seres desprovidos de diferenças.

Desse modo, há investidas de alguns discursos que operam com o pressuposto de um desenvolvimento natural do indivíduo, inclusive e fortemente na área educacional, a partir de algumas concepçóes como a da infância pueril e da biologia como explicação do corpo e das suas relações com a cultura. Walkerdine (1998, p. 145) afirma que "as práticas 
Do corpo que distingue meninos e meninas na educação física escolar

pedagógicas, pois, estão totalmente saturadas com a noção de uma sequência normalizada de desenvolvimento da criança (...)". Ela problematiza a Psicologia do Desenvolvimento como um regime discursivo que produz verdades, seus sujeitos e suas práticas, de forma a, reiteradamente, alimentar suas possibilidades e sua autoridade no campo educacional. Tal regime localiza o conhecimento como capacidade, ao proceder à análise do desenvolvimento das mentes de forma naturalizada.

De maneira semelhante, uma suposta evolução em níveis sequenciais, articulada a uma progressão etária, também atravessa as falas na educação física escolar sobre o desenvolvimento motor dos/as estudantes, com a compreensão de que a maturação dos corpos permitiria o trabalho com determinadas habilidades, valências e conteúdos. Nesses planos, existe uma "progressão biologizada de desenvolvimento" (Walkerdine, op. cit., p. 170) que atravessa as compreensões de corpo, aprendizagens e histórias de possibilidades e impossibilidades na escola.

\section{Considerações finais}

No caso das justificativas para a separação, gênero e biologia articulam-se. Parece-me que, no contexto desta pesquisa, existe um momento na trajetória escolar em que se cresce e tudo aparece. Corpos diferenciam-se, repelem-se, separam-se; masculinidades e feminilidades emergem, e uma suposta referência de idade os identifica.

Entendendo gênero como um organizador da cultura (Meyer, 2003) e, ao mesmo tempo, como uma categoria que atravessa e constitui os sujeitos de forma ininterrupta ao longo da vida, não há aqui pretensões de identificar suas marcas, isto é, as diferentes formas de viver as masculinidades e as feminilidades como consequências de mudanças biológicas. Assim, problematizo os argumentos citados sobre as meninas e os meninos para justificar a impossibilidade de trabalho misto numa determinada idade.

A educação física escolar atualiza e significa de forma importante os níveis de movimentos, habilidades e jogos motores que devem ser enfatizados em determinadas idades, o que é explorado de maneiras distintas para meninos e meninas, principalmente em intensidade. Isso se dá, também, em função das possibilidades corporais diferenciadas e 
de construções de feminilidades e masculinidades mais adequadas ou não ao currículo esportivo, o que, no caso da separação e do universo investigado, é apresentado como a base curricular dessa disciplina na escola.

Os argumentos de que há uma idade da separação - pois meninos são mais corajosos e respondem bem aos treinamentos - e que, em aulas mistas, "um atrasa o outro", a lógica que se estabelece é a do masculino como regra, norma, padrão, ou seja, como representação ideal de aluno/ a nessa disciplina. As meninas não atingem esse padrão, elas estão antes, aquém do desejado. Nesse sentido, segundo Scott (1995, p. 86), o gênero, como "forma primária de dar significados às relações de poder", é significado no contexto discursivo da separação na educação física escolar como determinante nas relações de poder que se estabelecem entre meninos e meninas, naquele contexto. Não é de se estranhar que, em alguns formatos de separação, os meninos estejam nas quadras e as meninas ocupem outros espaços.

\section{Notas}

1. Não estou, aqui, negando a materialidade dos corpos, mas sim problematizando como essa concretude é significada, num exercício reiterado e constante que busca a fixação de determinados sentidos sobre os corpos, como se estes fossem a essência dos sujeitos.

2. Segundo reportagem assinada por Jane Gross e intitulada Para gays, asilos significam "volta ao armário", publicada originalmente no jornal norte-americano The New York Times e divulgada no site de notícias e entretenimento Terra, homossexuais idosos americanos estavam sendo excluídos, rejeitados e discriminados por outros pacientes heterossexuais em casas de repouso. A possibilidade de um isolamento social entre os homossexuais é muito maior, o que está se tornando motivo de preocupação das gerações mais jovens, segundo o jornal. Disponível em: <http://noticias.terra.com.br/mundo/interna/ 0,,OI1983314-EI8141,00.html>. Acesso: 20 out. 2007.

3. Sobre questões éticas no processo investigativo, os nomes dos/as professores/as entrevistados/as e de suas respectivas escolas foram alterados para garantir o anonimato do grupo de informantes, como foi contratado no Termo de Consentimento Livre e Esclarecido.

4. Esta pesquisa foi realizada com docentes do ensino fundamental de uma rede de ensino ciclada. A proposta dos ciclos de formação é diferenciada dos padrôes adotados no regime seriado. Para cada ciclo, utiliza-se uma letra (A, B ou C), ou seja, ao primeiro, atribui-se a letra A; ao segundo, a letra B; e, ao terceiro, a C. Os números ao lado de cada letra referem-se aos anos daquele ciclo. Por exemplo, uma turma de A30 está no terceiro ano do primeiro ciclo. Vale ressaltar que esta proposta se inscreve no ensino fundamental de nove anos.

Cad. Cedes, Campinas, vol. 32, n. 87, p. 187-197, mai.-ago. 2012

Disponível em <http://www.cedes.unicamp.br> 
Do corpo que distingue meninos e meninas na educação física escolar

\section{Referências}

CORAZZA, S. Pesquisa-ensino: o "hífen" da ligação necessária na formação docente. In: ESTEBAN, M.T.; ZACCUR, E. (Org.). Professora-pesquisadora: uma práxis em construção. Rio de Janeiro: DP\&A, 2002. p. 55-69.

GALLO, S. Foucault: (re)pensar a educação. In: RAGO, M.; VEIGANETO, A. (Org.). Figuras de Foucault. Belo Horizonte: Autêntica, 2006. p. 253-260.

HALL, S. A centralidade da cultura: notas sobre a revolução de nosso tempo. Educação \& Realidade, Porto Alegre, v. 22, n. 2, p. 15-46, jul./ dez. 1997.

MEYER, D.E.E. Gênero e educação: teoria e política. In: GOELLNER, S.V.; NECKEL, J.; LOURO, G.L. (Org.). Corpo, gênero e sexualidade: um debate contemporâneo na educação. Petrópolis: Vozes, 2003. p. 9-27.

SANT'ANNA, D.B. Descobrir o corpo: uma história sem fim. Educação \& Realidade, Porto Alegre, v. 25, n. 2, p. 49-58, jul./dez. 2000.

SANT'ANNA, D.B. É possível realizar a história do corpo? In: SOARES, C.L. (Org.). Corpo e história. Campinas: Autores Associados, 2006. p. 3-24.

SCOTT, J. Gênero: uma categoria útil de análise histórica. Educação \& Realidade, Porto Alegre, v. 20, n. 2, p. 71-100, jul./dez. 1995.

SILVA, T.T. Teoria cultural e educação: um vocabulário crítico. Belo Horizonte: Autêntica, 2000.

SILVA, T.T. Documentos de identidade: uma introdução às teorias do currículo. Belo Horizonte: Autêntica, 2005.

SOARES, C.L. Corpo, conhecimento e educação: notas esparsas. In: SOARES, C.L. (Org.). Corpo e história. Campinas: Autores Associados, 2006. p. 109-130.

VEIGA-NETO, A. As idades do corpo: (material)idades, (divers)idades, (corporal)idades, (ident)idades... In: AZEVEDO, J.C. et al. Utopia de democracia na educação cidadã. Porto Alegre: Editora da UFRGS; Secretaria Municipal de Educação, 2000. p. 215-234. 
WALKERDINE, V. Uma análise foucaultiana da pedagogia construtivista. In: SILVA, T.T. (Org.). Liberdades reguladas: a pedagogia construtivista e outras formas de governo do eu. Petrópolis: Vozes, 1998. p. 143-216.

WALKERDINE, V. A cultura popular e a erotização das garotinhas. Educação \& Realidade, Porto Alegre, v. 24, n. 2, p. 75-88, jul./dez. 1999.

Recebido em 5 de abril de 2011.

Aprovado em 30 de junho de 2012. 